\title{
Produção de aquênio do girassol irrigado com água salobra
}

\author{
Kaline D. Travassos ${ }^{1}$, Frederico A. L. Soares ${ }^{2}$, H ans R. G heyi ${ }^{3}$, Débora R. S. Silva ${ }^{4}$, \\ Ana K. S. do N ascimentos \& Nildo da S. D ias ${ }^{6}$
}

\begin{abstract}
RESU MO
O bjetivou-se com este trabalho verificar os componentes de produção e a produção de aquênios do girassol (Helianthus annuus L., variedade Embrapa 122/V-2000), sob irrigação com diferentes níveis de salinidade de água em ambiente protegido. $0 \mathrm{~s}$ tratamentos foram compostos de seis níveis de salinidade da água de irrigação $\left(C E_{a}\right): N_{1}-0,5 ; N_{2}-1,0 ; N_{3}-2,0 ; N_{4}-3,0 ; N_{5}-4,0$ e $N_{6}-5,0$ dS m-1 a $25{ }^{\circ} C$, em delineamento inteiramente casualizado com 5 repetições. Avaliaram-se: o diâmetro interno do capítulo, número de aquênios, massa de 100 aquênios, massa total de aquênios, fitomassa seca da parte aérea e da raiz, relação fitomassa seca da raiz e da parte aérea, consumo de água, condutividade elétrica da água drenada e do extrato de saturação do solo. A massa total de aquênios e o número de aquênios decresceram de 11,39 e 9,64\%, respectivamente, por aumento unitário da condutividade elétrica da água de irrigação; a fitomassa seca da raiz foi mais afetada pela salinidade da água de irrigação que a fitomassa seca da parte aérea, os níveis de salinidade da água de drenagem no final do experimento foi cerca de 2,2 vezes da condutividade elétrica do extrato de saturação.
\end{abstract}

Palavras-chave: Helianthus annuus L., salinidade, condutividade elétrica

\section{Achene production of the sunflower irrigated with brackish water}

\begin{abstract}
The aim of this study was to determine yield components and achene production of sunflower (Helianthus annuus L.) variety Embrapa $122 \mathrm{~N}-2000$ irrigated with water of different salinities in a greenhouse. The treatments consisted of six levels of salinity of irrigation water $\left(\mathrm{EC}_{\mathrm{w}}\right), \mathrm{N}_{1}-0.5, \mathrm{~N}_{2}-1.0 ; \mathrm{N}_{3}-2.0 ; \mathrm{N}_{4}-3.0 ; \mathrm{N}_{5}$

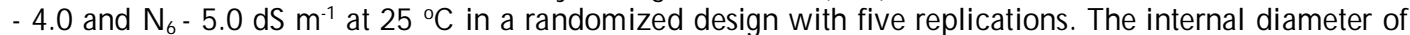
the chapter, number of seeds, weight of 100 seeds, the total mass of seeds, dry weight of shoot and root, ratio of dry weight of root and shoot, water consumption, electrical conductivity of drainage water and the saturation extract of soil. The total mass of seeds and number of seeds decreased 11.39 and $9.64 \%$, respectively, with per unit increase in electrical conductivity of irrigation water, the root dry mass was more affected by salinity of irrigation water than dry mass of aerial parts, salinity levels of drainage water at the end of experiment were about 2.2 times of electrical conductivity of saturation extract.
\end{abstract}

Key words: Helianthus annuus L, salinity, electric conductivity

Trabalho submetido e selecionado no primeiro Simpósio Brasileiro de Salinidade realizado de 12-15/10/2010 em Fortaleza, Ceará, Brasil ${ }^{1}$ D outoranda, U nidade Acadêmica de Engenharia Agrícola (UAEA), Universidade Federal de Campina Grande (UFCG), Campina Grande, PB. CEP 58400-000. Fone: (83) 2101-1056. E-mail: kalinedantas@yahoo.com.br

2 IFGO, Rio Verde, GO. CEP 75900-000. E-mail: fredalsoares@hotmail.com

${ }^{3} \mathrm{~N}$ úcleo de Engenharia de Água e Solo, Universidade Federal do Recôncavo da Bahia, U FRB, CEP 44380-000. Cruz das Almas, BA. E-mail: hans@deag.ufcg.edu.br

${ }^{4}$ Mestre em Engenharia Agrícola, UFCG. E-mail: debly 22@hotmail.com

${ }^{5}$ Tecnólogo em Recursos Hídricos, Bolsista DTI, Escola Superior de Agricultura Luiz de Q ueiroz, Instituto Nacional de Ciência e Tecnologia em Engenharia da Irrigação, CEP 13400-000 Piracicaba, SP. E-mail: kelly_s02@hotmail.com

${ }^{6}$ Departamento de Ciências Ambientais/U FERSA, CEP 59600-000 Mossoró, RN. E-mail: nildo@ufersa.edu.br 


\section{INTRODUÇÃO}

Devido à sua ampla adaptabilidade a diversas condições edafoclimáticas, o girassol (Helianthus annuus L.) é uma cultura muito importante (Monotti, 2004). No Brasil, uma grande parte do território é considerada apta para o cultivo de girassol, sendo tolerante à seca mais que a maioria das espécies normalmente cultivadas; além da baixa incidência de pragas e doenças (Albuquerque et al., 2001).

O cultivo do girassol se destaca como a quarta oleaginosa em produção de grãos e a quinta em área cultivada no mundo; entretanto, a área sob o cultivo de girassol no Brasil aumentou até 2008; a partir daí, começou a ter redução na sua produção, alcançando 96,835 t de grãos no ano de 2009 (IBGE, 2010). O Brasil é um produtor pouco expressivo de girassol (aquênios), tendo participado com aproximadamente $0,5 \%$ da produção mundial nos últimos anos (Fagundes, 2002), fato que mudou com a implantação do Programa Nacional de Biocombustíveis em 2002, pelo Governo Federal, visando beneficiar grande número de agricultores no Nordeste estimulando o cultivo de culturas oleaginosas, entre elas o girassol.

Em várias partes do mundo a agricultura está enfrentando um sério problema de disponibilidade de recursos hídricos adequados, forçando muitos agricultores a utilizarem água com concentração de sais relativamente alta para a irrigação das culturas (Savvas et al., 2007). Em muitas áreas de produção agrícola o uso de água de baixa qualidade na irrigação e o manejo inadequado de fertilizantes minerais, são as maiores causas dos problemas de salinidade dos solos cultivados.

O uso de águas salinas na irrigação para produção vegetal é um desafio que vem sendo superado com sucesso em diversas partes do mundo, graças à utilização de espécies tolerantes e à adoção de práticas adequadas de manejo da cultura, do solo e da água de irrigação (Rhoades et al., 2000). Segundo Neves et al. (2009), na região semiárida brasileira é comum a utilização de fontes de água com alta concentração de sais, sobretudo de sódio. Várias pesquisas têm demonstrado que as culturas respondem diferentemente à salinidade; algumas produzem rendimentos economicamente aceitáveis sob altos níveis de salinidade, enquanto outras são sensíveis a níveis relativamente baixos (Mittova et al., 2002; Caruso \& Villari, 2004; Rubio et al., 2009; Al-Karaki et al., 2009).

A melhor capacidade de adaptação osmótica que algumas culturas permitem absorver, mesmo em condições de salinidade, maior quantidade de água (Ayers \& Westcot, 1999; Santana et al., 2007). Entretanto, esta adaptação depende de muitos outros fatores como espécie, cultivar, estádio fenológico, características dos sais, intensidade e duração do estresse salino, manejo cultural e da irrigação e condições edafoclimáticas (Ashraf \& Harris, 2004; Tester \& Davenport, 2003).

Neste contexto, a utilização da águas salinas na agricultura deve ser considerada uma alternativa importante, tendo em vista a escassez de água de boa qualidade. Porém existem poucos relatos sobre a tolerância ao estresse salino no girassol (Liu \& Baird, 2003). Segundo Katerji et al. (2000), o girassol é uma cultura moderadamente sensível a salinidade porém ainda não se estudou sua tolerância quanto à produção de sementes sob o efeito de água salobra, nas condições semiáridas do Brasil.

Deste modo, objetivou neste trabalho verificar os componentes de produção e a produção de aquênios do girassol (Helianthus annuus L.) variedade Embrapa 122/V-2000, sob irrigação com diferentes níveis de salinidade de água em ambiente protegido.

\section{MATERIAL E MÉTODOS}

O trabalho foi desenvolvido em casa de vegetação pertencente à Unidade Acadêmica de Engenharia Agrícola, do Centro de Tecnologia e Recursos Naturais, da Universidade Federal de Campina Grande, Campus I, em Campina Grande, $\mathrm{PB}$, Brasil. O delineamento experimental utilizado foi o inteiramente casualizado com 6 níveis de salinidade da água de irrigação $\left(\mathrm{CE}_{\mathrm{a}}\right): \mathrm{N}_{1}-0,5 ; \mathrm{N}_{2}-1,0 ; \mathrm{N}_{3}-2,0 ; \mathrm{N}_{4}-3,0 ; \mathrm{N}_{5}-4,0$ e $\mathrm{N}_{6}$ $-5,0 \mathrm{dS} \mathrm{m}^{-1}$ a $25^{\circ} \mathrm{C}$, com 5 repetições, compostas por vasos de capacidade de $24 \mathrm{~L}$, arranjados triangularmente em fileiras duplas, espaçadas $0,60 \mathrm{~m}$ entre fileira simples, $0,50 \mathrm{~m}$ entre plantas em fileira e 1,00 m entre fileiras duplas.

Para se obter as águas com condutividade elétrica desejada para as irrigações, adicionou-se o $\mathrm{NaCl}$ comercial (sem iodo) na água do sistema de abastecimento local de Campina Grande, PB (CAGEPA). A quantidade de cloreto de sódio (Q $\mathrm{NaCl}$ ) utilizado no preparo da água foi determinada considerando-se a condutividade elétrica inicial da água, conforme a Eq. 1 de Richards (1954):

$$
\mathrm{Q} N \mathrm{NaCl}\left(\mathrm{mg} \mathrm{L}^{-1}\right)=640 \times\left(\mathrm{CE}_{\mathrm{a}} \text { desejada }-\mathrm{CE}_{\mathrm{a}} \text { inicial }\right)
$$

em que:

$\mathrm{CE}_{\mathrm{a}}$ - condutividade elétrica da água, em dS m ${ }^{-1}$.

A variedade de girassol utilizada foi a Embrapa 122/V-2000, cujas sementes foram cedidas pela Embrapa Soja. Semearamse para obtenção das mudas de girassol, três sementes por tubetes plásticos preenchidos com a mistura de um substrato comercial (Hortimix) contendo superfosfato simples, nitrato de potássio, turfa, vermiculita e casca de pinus e de um solo franco arenoso, na proporção de uma parte de terra para uma parte de substrato; dos 2 aos 8 dias após semeadura (DAS) utilizou-se, durante esse período água de chuva $\left(\mathrm{CE}_{\mathrm{a}}=0,01 \mathrm{dS} \mathrm{m}^{-1}\right)$ na irrigação, 2 vezes ao dia, iniciando-se aos 8 DAS, as irrigações com respectivas água salina nos tratamentos.

Antes do transplantio fez-se uma irrigação, aplicando-se volume do respectivo tratamento, suficiente para que o solo nos vasos atingisse capacidade de campo. Os vasos em que as plântulas de girassol foram transplantados estavam preenchidos com uma camada de $800 \mathrm{~g}$ de brita $\mathrm{n}^{\mathrm{o}} 1 \mathrm{e}$ posteriormente com $24 \mathrm{~kg}$ de um material de solo do tipo Latossolo franco-arenoso destorroado, sendo adicionados na camada superior $(10 \mathrm{~cm}), 2 \%$ (em base do peso) de húmus, correspondendo a uma massa de 480 g por vaso. O transplantio para os vasos foi realizado aos 15 DAS, quando as plântulas estavam com duas folhas definitivas. As irrigações foram feitas 
no início da manhã e cada tratamento recebeu um volume de irrigação em intervalos de rega de 2 dias. O volume de água a ser aplicado foi calculado em função da demanda evapotranspiratória, sendo esta estimada para intervalos médios de 10 dias; para a adubação, utilizou-se a quantidade recomendada por Novais et al. (1991) para experimentos em casa de vegetação.

Durante o experimento não ocorreu presença de ervas invasoras, eliminado-se manualmente as que, por ventura, surgiam; para o controle da mosca branca e minadora foram realizadas 2 pulverizações com inseticidas sistêmicos ciromazina (Trigard) na proporção de uma solução contendo $0,60 \mathrm{~g} \mathrm{~L}^{-1}$ $(0,02 \%)$ e tiametoxam (Actara) na proporção de $2 \mathrm{~g} \mathrm{~L}^{-1}(0,2 \%)$, realizaram-se também, 4 pulverizações de lambda-cialotrina (Karate), na proporção de $2 \mathrm{~mL} \mathrm{~L}^{-1}(0,2 \%)$ e 1 pulverização de fungicida tebuconazole (Rival) na proporção de $10 \mathrm{mLL}^{-1}(1 \%)$.

Como o experimento foi conduzido em casa de vegetação, impossibilitando a polinização natural, empregou-se a polinização artificial cruzada, que consistiu em se utilizar a ponta dos dedos com uma boa quantidade de pólen proveniente de diversas flores produzidas por plantas diferentes para, em seguida, se realizar um rápido toque com as pontas dos dedos em relação à base da flor, procurando-se atingir todos os estigmas (Ruggiero et al., 1998).

Na colheita avaliou-se diâmetro interno do capítulo (DI), massa total de aquênios (MA), massa de 100 aquênios (M100A), número de aquênios (NA), fitomassa seca da parte aérea (FSPA), da raiz (FSR), relação fitomassa seca da raiz e da parte aérea (R/PA), consumo de água, condutividade elétrica da água drenada $\left(\mathrm{CE}_{\mathrm{d}}\right)$ e do extrato de saturação do solo $\left(\mathrm{CE}_{\mathrm{es}}\right)$. Considerou-se diâmetro interno do capítulo uma linha imaginária na parte fertilizada do receptáculo floral, onde foram feitas leituras na horizontal e na vertical com auxílio de régua graduada, sempre no dia em que a flor estava totalmente aberta. Utilizando-se uma balança digital eletrônica foram pesados todos os aquênios produzidos e a pesagem dos 100 aquênios (escolhidos aleatoriamente) bem como a contagem manual do número de aquênios total produzidos.
Para avaliação da FSPA as plantas foram cortadas rentes à superfície do solo. No caso das raízes, estas foram cuidadosamente separadas do solo por meio de um jato de água passada em peneira com malha de 2,0 mm. Após coletadas tanto a parte aérea como as raízes, foram colocadas em estufa de circulação forçada de ar, a $60^{\circ} \mathrm{C}$, até atingirem peso constante, sendo pesados em seguida, em uma balança digital eletrônica.

Durante o período experimental, a cada 10 dias, fez-se a coleta da água drenada em todos os vasos, a fim de se determinar os valores médios da fração de lixiviação $\quad(\mathrm{FL}=$ volume drenado / volume aplicado), do consumo da água pela planta (CA = volume aplicado - volume drenado); determinouse a condutividade elétrica da água de drenagem para cálculo do fator de concentração $\left(\mathrm{FC}=\mathrm{CE}_{\mathrm{d}} / \mathrm{CE}_{\mathrm{a}}\right)$.

Ao final do experimento foram retiradas, em todos os tratamentos, amostras do solo na camada de $0-30 \mathrm{~cm}$ para as análises químicas. Todas as análises foram feitas no Laboratório de Irrigação e Salinidade do Solo, da Universidade Federal de Campina Grande, PB, Campus I, determinado-se o pH da pasta de saturação, a condutividade elétrica do extrato de saturação $\left(\mathrm{CE}_{\mathrm{es}}\right)$ a $25^{\circ} \mathrm{C}$, os cátions $\left(\mathrm{Ca}^{++}, \mathrm{Mg}^{++}, \mathrm{K}^{+}\right.$e $\left.\mathrm{Na}^{+}\right)$e os ânions $\left(\mathrm{Cl}^{-}\right.$, $\mathrm{CO}_{3}^{-}$e $\mathrm{HCO}_{3}^{-}$) solúveis, utilizando-se as metodologias propostas por Richards (1954) e pela EMBRAPA (1997).

Os dados obtidos foram submetidos à análise de variância (teste F), aplicando-se análise de regressão polinomial para os níveis de salinidade da água de irrigação, quando significativos. Como as variâncias dos diferentes níveis salinos não foram estatisticamente homogêneas, os dados de DI, MA, NA e M100A, foram transformados em $\sqrt{\mathrm{x}}$ (Ferreira, 2000).

\section{RESULTADOS E DISCUSSÃO}

Conforme o resumo da análise de variância, houve efeito significativo da salinidade da água de irrigação sobre as variáveis número de aquênios (NA), massa total de aquênios (MA), fitomassa seca da parte aérea (FSPA) e da raiz (FSR). De acordo com as médias apresentadas na Tabela 1 , o maior

Tabela 1. Resumo das análises de variância e médias para o diâmetro interno do capítulo (DI), número de aquênios por capítulo (N A), massa de 100 aquênios (M 100A), massa total de aquênios por planta (M A), fitomassa seca da parte aérea (FSPA), da raiz (FSR) e a relação fitomassa seca da raiz e da parte aérea (R/PA) do girassol irrigado com água de diferentes condutividades elétrica $\left(\mathrm{CE}_{\mathrm{a}}\right)$

\begin{tabular}{|c|c|c|c|c|c|c|c|c|}
\hline \multirow{2}{*}{ Causa de variação } & \multirow{2}{*}{ GL } & \multicolumn{7}{|c|}{ Quadrado médio } \\
\hline & & $\mathbf{D I}^{1}$ & $\mathrm{NA}^{1}$ & $\mathrm{M100A}^{1}$ & MA $^{1}$ & FSPA $^{1}$ & FSR $^{1}$ & $R / P^{1}$ \\
\hline $\begin{array}{l}\text { Salinidade - } \mathrm{CE}_{\mathrm{a}} \\
\text { Resíduo }\end{array}$ & $\begin{array}{c}5 \\
24\end{array}$ & $\begin{array}{c}0,14^{\text {ns }} \\
0,11\end{array}$ & $\begin{array}{c}37,95 * \\
12,51\end{array}$ & $\begin{array}{c}0,09^{\text {ns }} \\
0,12\end{array}$ & $\begin{array}{c}3,65 * * \\
0,79\end{array}$ & $\begin{array}{c}7,57 * * \\
0,59\end{array}$ & $\begin{array}{c}3,64 * * \\
0,16\end{array}$ & $\begin{array}{c}0,07^{\text {ns }} \\
0,03\end{array}$ \\
\hline $\mathrm{CV}$ & & 12,72 & 18,22 & 12,97 & 16,66 & 12,39 & 15,96 & 41,09 \\
\hline \multirow{2}{*}{ Salinidade - $C E_{a}\left(d S m^{-1}\right)$} & & \multicolumn{7}{|c|}{ Médias $^{2}$} \\
\hline & & $\mathrm{cm}$ & & g & g & g & g & g \\
\hline 0,5 & & 7,81 & 600,00 & 7,96 & 46,73 & 66,26 & 16,24 & 0,49 \\
\hline 1,0 & & 7,47 & 422,80 & 7,25 & 30,82 & 45,29 & 7,86 & 0,26 \\
\hline 2,0 & & 6,93 & 319,80 & 9,08 & 29,89 & 47,01 & 6,96 & 0,14 \\
\hline 3,0 & & 6,98 & 402,00 & 7,65 & 28,99 & 33,77 & 5,40 & 0,15 \\
\hline 4,0 & & 6,00 & 319,00 & 7,94 & 23,92 & 28,24 & 3,50 & 0,13 \\
\hline 5,0 & & 5,47 & 297,40 & 6,83 & 18,41 & 22,54 & 2,69 & 0,12 \\
\hline
\end{tabular}

** significativo a 0,01 de probabilidade; * significativo a 0,05 de probabilidade; $\mathrm{ns}$ - não significativo; pelo teste " $\mathrm{F}$ "

1 dados apresentados estão transformados em $\sqrt{\mathrm{x}}$

${ }^{2}$ médias apresentadas com os dados originais 
diâmetro interno do capítulo (DI) foi obtido no tratamento com condutividade elétrica da água de irrigação $\left(\mathrm{CE}_{\mathrm{a}}\right)$ de $0,5 \mathrm{dS} \mathrm{m}{ }^{-1}$ $(7,81 \mathrm{~cm})$ e o menor com $\mathrm{CE}_{\mathrm{a}}$ de $5,0 \mathrm{dS} \mathrm{m}^{-1}(5,47 \mathrm{~cm})$. Esta variável é importante para a produção de aquênios de girassol, pois quanto maior o diâmetro interno do capítulo, mais aquênios conterá a planta.

Com relação à massa de 100 aquênios, observa-se que a massa máxima alcançada foi de $9,08 \mathrm{~g}$ para a $\mathrm{CE}_{\mathrm{a}} \mathrm{de} 2,0 \mathrm{dS} \mathrm{m}{ }^{-1}$ e a mínima de 6,83 g com a $\mathrm{CE}_{\mathrm{a}}$ de 5,0 $\mathrm{dS} \mathrm{m}^{-1}$ (Tabela 1). A massa de 100 aquênios para esta cultivar é de $6 \mathrm{~g}$, valor este inferior ao obtido no nível mais salino da água de irrigação. Com relação à massa de 100 aquênios, Biscaro et al. (2008), obtiveram massa de 7,19 g, valor muito próximo ao alcançado na $\mathrm{CE}_{\mathrm{a}} \mathrm{de} 5,0 \mathrm{dS} \mathrm{m}^{-1}$ no presente estudo.

De acordo com a análise de regressão, ocorreu decréscimo linear na massa total de aquênios, registrando-se perdas de $11,39 \%$ por aumento unitário da condutividade elétrica da água de irrigação (Figura 1A). Considerando-se que a massa total de aquênio é o resultado da capacidade da planta de suprir nutrientes, as plantas irrigadas com $\mathrm{CE}_{\mathrm{a}}$ de $5 \mathrm{dS} \mathrm{m}^{-1}$ perderam aproximadamente $57 \%$ de sua capacidade.

Para a variável número de aquênios, este decréscimo unitário por aumento da $\mathrm{CE}_{\mathrm{a}}$ foi de $9,64 \%$ (Figura 1B). As plantas produziram número de aquênio entre 600 e 297 aquênios entre o nível de salinidade da água de irrigação mais baixo para o mais alto, respectivamente. Katerji et al. (2000), na produção do girassol sob condições de diferentes $\mathrm{CE}_{\mathrm{a}}$ obtiveram um decréscimo de $56,12 \%$ quando se irrigou com uma água de $\mathrm{CE}$ de $3,9 \mathrm{dS} \mathrm{m}^{-1}$ em relação à água de $\mathrm{CE}$ de $0,8 \mathrm{dS} \mathrm{m}^{-1}$, decréscimo muito superior ao encontrado neste estudo.

A fitomassa seca da parte aérea (FSPA) foi influenciada significativamente pela salinidade da água de irrigação, de forma linear, com decréscimo de $13,56 \%$ por aumento unitário da condutividade elétrica da água de irrigação (Figura 1C); esta redução de fitomassa seca também foi verificada por Silva et al. (2009), em consequência do aumento da salinidade do solo.

Segundo Flowers (2004), a inibição do crescimento de plantas sob estresse salino pode ser explicada pela redução do potencial osmótico da solução do solo, além da possibilidade de ocorrência de toxicidade iônica, desequilíbrio nutricional, ou ambos, em função da acumulação em excesso de determinados íons nos tecidos vegetais. As plantas tendem a fechar os estômatos para reduzir as perdas de água por transpiração, resultando em uma taxa fotossintética menor e contribuindo para a redução do crescimento das espécies sob tal estresse.

Para a fitomassa seca da raiz também houve efeito da salinidade da água de irrigação de forma linear, com decréscimo de $18,37 \%$ por incremento unitário da condutividade elétrica da água de irrigação (Figura 1D); esta redução da fitomassa seca da raiz foi observada também por Nobre et al. (2010); esta influência da $\mathrm{CE}_{\mathrm{a}}$ ser maior na fitomassa seca da raiz pode ser comprovada pela relação fitomassa seca da raiz pela parte aérea, pois ocorreu um decréscimo de $46,93 \%$ na relação R/PA das plantas irrigadas com água de CE de $1,0 \mathrm{dS} \mathrm{m}^{-1}$ quando comparadas com a relação das plantas irrigadas com água de $\mathrm{CE}$ de $0,5 \mathrm{dS} \mathrm{m}^{-1}$, ficando evidente que a salinidade afetou mais a FSR do que a FSPA.
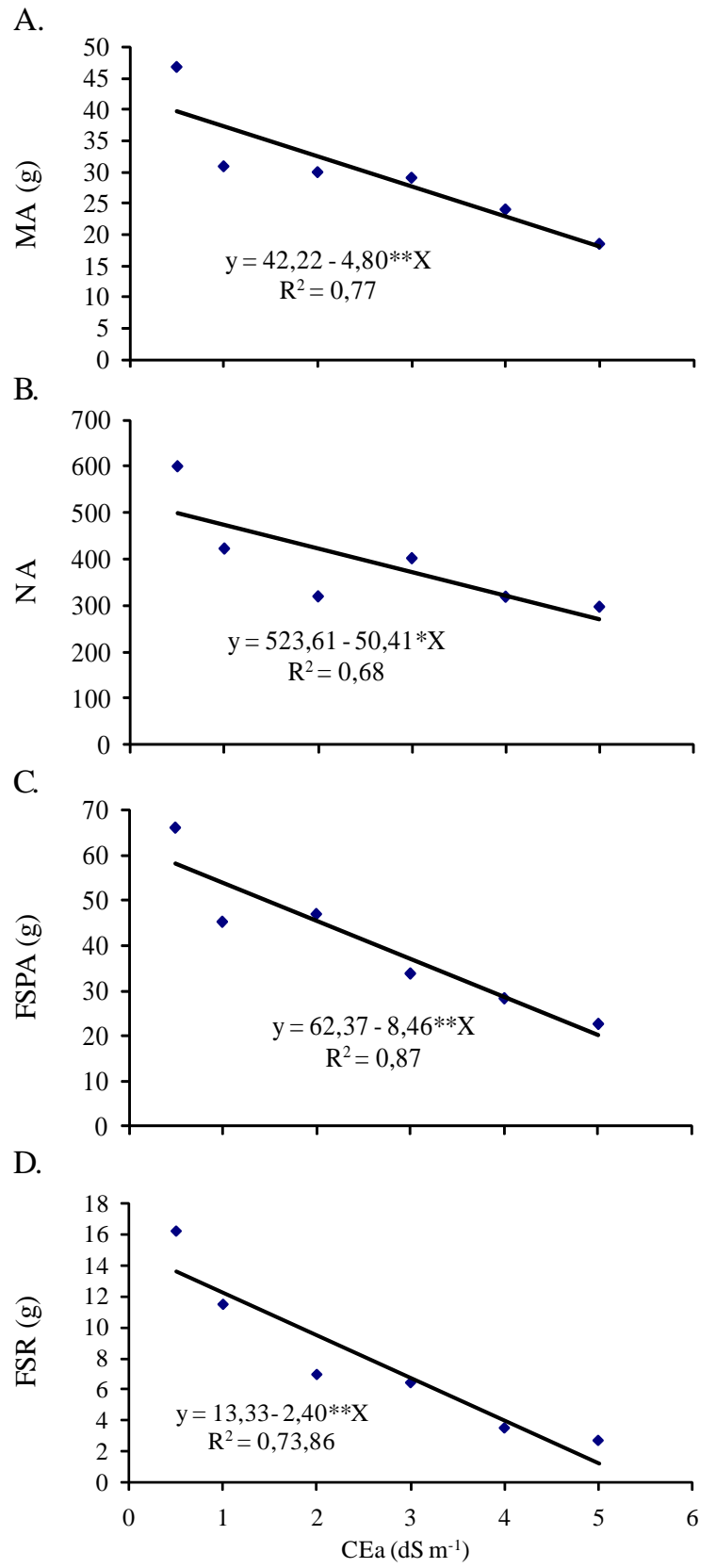

Figura 1. Massa total de aquënio ( $M A)$, número de aquênio (NA), fitomassa seca parte aérea (FSPA) e fitomassa seca da raiz (FSR) do girassol, em função da condutividade elétrica da água utilizada na irrigação $\left(\mathrm{CE}_{\mathrm{a}}\right)$

Verificou-se decréscimo de 9,49\% por aumento unitário da condutividade elétrica da água de irrigação no consumo de água pelas plantas (Figura 2A), ou seja, para cada $1 \mathrm{dS} \mathrm{m}^{-1}$ acrescentado na água de irrigação estima-se, pela equação de regressão, que a planta reduziu 4,3 L de água em seu consumo, durante o ciclo. Tal fato se deve, em parte, à redução do potencial osmótico da solução nos maiores níveis de salinidade, sendo comprovado pelo aumento da condutividade elétrica da água de drenagem $\left(\mathrm{CE}_{\mathrm{d}}\right)$ das plantas irrigadas com $\mathrm{CE}_{\mathrm{a}}$ de 5,0 $\mathrm{dS} \mathrm{m}^{-1}$, que foi 5 vezes maior que a $\mathrm{CE}_{\mathrm{d}}$ das plantas irrigadas com $\mathrm{CE}_{\mathrm{a}}$ de $0,5 \mathrm{dS} \mathrm{m}^{-1}$ (Figura 2B) e, consequentemente, isto fez com que a condutividade elétrica do extrato de saturação do solo $\left(\mathrm{CE}_{\mathrm{es}}\right)$ aumentasse. 
A.

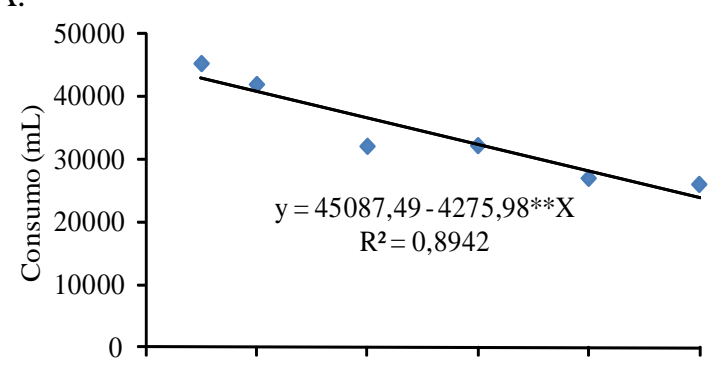

B.

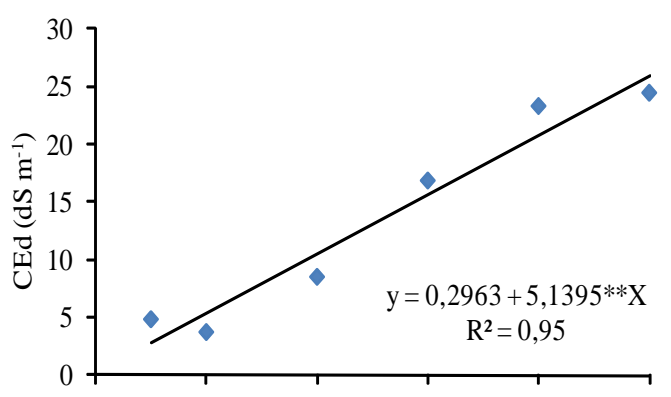

C.

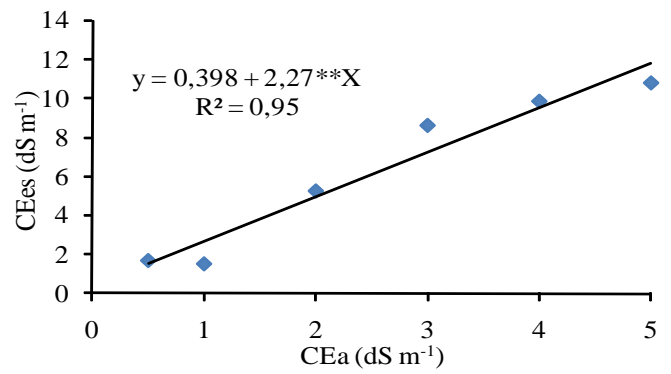

D.

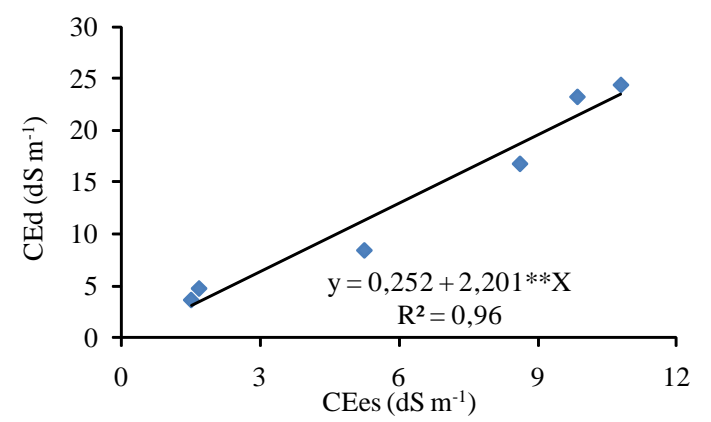

Figura 2. Consumo de água (Consumo) $(A)$, condutividade elétrica da água drenada $\left(C E_{d}\right)(B)$, condutividade elétrica do extrato de saturação do solo $\left(C E_{\mathrm{es}}\right)(C)$ em função da condutividade elétrica da água de irrigação e a condutividade elétrica da água drenada $\left(C E_{d}\right)(D)$ em função da condutividade elétrica do extrato de saturação do solo $\left(\mathrm{CE}_{\mathrm{es}}\right)$

De acordo com a equação de regressão (Figura $2 \mathrm{C}$ ), a $\mathrm{CE}_{\mathrm{es}}$ no tratamento com $\mathrm{CE}_{\mathrm{a}}$ de $5,0 \mathrm{dS} \mathrm{m}^{-1}$, foi 7 vezes maior que a $\mathrm{CE}_{\mathrm{es}}$ dos vasos irrigados com água de menor salinidade $\left(0,5 \mathrm{dS} \mathrm{m}^{-1}\right)$. $\mathrm{O}$ valor médio de concentração, conforme determinado, foi de 2,2 em relação ao $\mathrm{CE}_{\mathrm{a}}$. Ayers \& Westcot (1999), relatam que este fator é igual a 1,6 para uma fração de lixiviação igual a 0,15 , enquanto a relação entre $\mathrm{CE}_{\mathrm{d}}$ e $\mathrm{CE}_{\mathrm{es}}$ é aproximadamente igual a 2, valor muito próximo, obtido neste experimento, visto que, segundo a equação de regressão, o valor foi igual a 2,2, como pode ser visto na Figura 2D. Esta incoerência talvez seja pelo fato do experimento ter sido realizado nos vasos com irrigação diária na ultima fase de produção com altos volumes e sem fração de lixiviação. Assim, a última lixiviação realizada no final do ciclo, apresentou valor de $\mathrm{CE}_{\mathrm{d}}$, relativamente elevada. Observou-se, neste trabalho, que as frações de lixiviação final foram de 0,11 para $0,5 \mathrm{dS} \mathrm{m}^{-1}$ e de 0,19 para a $\mathrm{CE}_{\mathrm{a}}$ de $5,0 \mathrm{dS} \mathrm{m}^{-1}$.

Comparando as análises das características químicas do solo antes e depois de um ciclo cultural do girassol (Tabela 2), verifica-se um acréscimo em todas as características analisadas; o teor de $\mathrm{Na}$ no início do experimento representava apenas $2,73 \%$ do teor de $\mathrm{Na}$ no final do experimento, quando se irriga com uma $\mathrm{CE}_{\mathrm{a}}$ de $5,0 \mathrm{dSm}^{-1}$; já o valor de $\mathrm{Cl}$ foi de $3,08 \%$ à medida em que se aumentou a condutividade elétrica da água de irrigação, variando de 7,29 mmol $_{c} \mathrm{~L}^{-1}$ e a 73,58 $\mathrm{mmol}_{\mathrm{c}} \mathrm{L}^{-1}$. Em consequência deste aumento, os valores da Relação de Adsorção de Sódio (RAS) no final do experimento aumentaram proporcionalmente com a salinidade da água para os diferentes níveis, sobretudo nos tratamentos a partir de $\mathrm{CE}_{\mathrm{a}}=3,00 \mathrm{dS} \mathrm{m}^{-1}$ em que valores de RAS chegam a ser superiores a 20, implicando que o valor correspondente da PST seria superior a 15, fato este relacionado com a composição da água de irrigação, uma vez que foi preparada, na sua totalidade, com $\mathrm{NaCl}$, o que proporciona aumento da RAS.

Tabela 2. Resultados médios das análises acidez $(\mathrm{pH})$, condutividade elétrica (CE), cálcio (Ca), magnésio $(\mathrm{Mg})$, sódio $(\mathrm{Na})$, potássio $(\mathrm{K})$, cloreto $(\mathrm{Cl})$, sulfato $\left(\mathrm{SO}_{4}\right)$, carbonato $\left(\mathrm{CO}_{3}\right)$, bicarbonato $\left(\mathrm{HCO}_{3}\right)$, relação de adso rção de sódio (RAS) do extrato de saturação do solo ao final do experimento

\begin{tabular}{|c|c|c|c|c|c|c|c|}
\hline \multirow{2}{*}{ Características } & \multirow{2}{*}{ SI } & \multicolumn{6}{|c|}{ Níveis de salinos ( $\mathrm{dS} \mathrm{m}^{-1}$ ) } \\
\hline & & 0,5 & 1 & 2 & 3 & 4 & 5 \\
\hline $\mathrm{ph}$ & 5,60 & 7,15 & 7,20 & 6,93 & 7,08 & 7,10 & 7,15 \\
\hline $\mathrm{CE}\left(\mathrm{dS} \mathrm{\textrm {m } ^ { - 1 } )}\right.$ & 0,67 & 1,68 & 1,52 & 5,25 & 8,61 & 9,85 & 10,79 \\
\hline $\mathrm{Ca}\left(\mathrm{mmol}_{\mathrm{L}} \mathrm{L}^{-1}\right)$ & 2,10 & 3,21 & 1,84 & 7,00 & 5,45 & 6,03 & 5,92 \\
\hline $\mathrm{Mg}\left(\mathrm{mmol}_{\mathrm{c}} \mathrm{L}^{-1}\right)$ & 1,90 & 3,82 & 2,54 & 6,68 & 6,03 & 6,22 & 14,08 \\
\hline $\mathrm{Na}\left(\mathrm{mmol}_{\mathrm{L}} \mathrm{L}^{-1}\right)$ & 2,01 & 7,29 & 7,90 & 33,10 & 59,23 & 67,88 & 73,58 \\
\hline $\mathrm{K}\left(\mathrm{mmol}_{\mathrm{c}} \mathrm{L}^{-1}\right)$ & 0,25 & 0,39 & 0,39 & 0,79 & 0,88 & 0,98 & 1,12 \\
\hline $\mathrm{CO}_{3}\left(\mathrm{mmol}_{\mathrm{c}} \mathrm{L}^{-1}\right)$ & 0,00 & 0,00 & 0,00 & 0,00 & 0,00 & 0,00 & 0,00 \\
\hline $\mathrm{HCO}_{3}\left(\mathrm{mmol}_{\mathrm{c}} \mathrm{L}^{-1}\right)$ & 2,78 & 3,27 & 3,00 & 3,57 & 4,09 & 3,68 & 3,75 \\
\hline $\mathrm{Cl}\left(\mathrm{mmol}_{\mathrm{c}} \mathrm{L}^{-1}\right)$ & 2,80 & 9,84 & 9,79 & 35,11 & 68,95 & 79,15 & 90,80 \\
\hline $\mathrm{SO}_{4}$ & A & $P$ & $P$ & $P$ & $P$ & $P$ & $\mathrm{P}$ \\
\hline RAS $\left(\mathrm{mmol} \mathrm{L}^{-1}\right)^{0,5}$ & 1,42 & 3,87 & 5,34 & 13,18 & 24,28 & 27,31 & 26,44 \\
\hline
\end{tabular}

Com os resultados das análises do extrato de saturação do solo no final do experimento (Tabela 2), verificaram-se incrementos para todos os cátions solúveis. A elevação mais acentuada do sódio e do cloreto ocorreu em virtude do $\mathrm{NaCl}$ ter sido utilizado na preparação das águas de irrigação. As altas concentrações desses íons em relação aos outros, podem causar toxicidade às plantas (Ayers \&Westcot, 1999).

\section{CONCLusõEs}

1. A massa total de aquênios e o número de aquênios decresceram em 11,39 e 9,64\%, respectivamente, por aumento unitário da condutividade elétrica da água de irrigação. 
2. A fitomassa seca da raiz foi mais afetada pela salinidade da água de irrigação que a fitomassa seca da parte aérea;

3. Os níveis de salinidade da água de irrigação utilizados no experimento proporcionam aumento de cerca de 2,2 vezes na condutividade elétrica do extrato de saturação.

\section{AgradeCIMENTOS}

À Coordenação de Aperfeiçoamento de Pessoal de Nível Superior (CAPES) e à Universidade Federal de Campina Grande, Campus I, pelo apoio financeiro; ao Dr Reginaldo Gomes Nobre, por apresentar sugestões no manuscrito.

\section{LITERATURA CITADA}

Albuquerque, M. C. de F. E.; Moro, F. V.; Fagioli, M.; Ribeiro, M. C. Testes de condutividade elétrica e de lixiviação de potássio na avaliação da qualidade fisiológica de sementes de girassol. Revista Brasileira de Sementes, v.23, p.1-8, 2001.

Al-Karaki, G.; Al-Ajmi, A.; Othman, Y. Response of soilless grown bell pepper cultivars to salinity. Acta Horticulturae, v.807, p.227-232, 2009.

Ashraf M.; Harris, P. J. C. Potential biochemical indicators of salinity tolerance in plants. Plant Science, v.166, p.3-16, 2004.

Ayers, R. S.; Westcot, D. W. A qualidade da água na agricultura. Campina Grande: UFPB, 1999. 218p. Estudos FAO - Irrigação e Drenagem, 29.

Biscaro, G. A.; Machado, J. R.; Tosta, M. D. A. S.; Mendonça, V.; Soratto, R. P.; Carvalho, L. A. Adubação nitrogenada em cobertura no girassol irrigado nas condições de CassilândiaMS. Ciência Agrotecnologia, v.32, p. 1366-1373, 2008.

Caruso, G.; Villari, G. Effect of EC-level and plant shading on the NFT-grown "Friariello Pepper". Acta Horticulturae, v.659, p.576-585, 2004.

EMBRAPA - Empresa Brasileira de Pesquisa Agropecuária. EMBRAPA 122- V2000, 1997. Folder girassol

Fagundes, M. H. Sementes de girassol: Alguns comentários. http://www.conab.gov.br. 10 Out. 2002.

Ferreira, P. V. Estatística experimental aplicada à agronomia. 2.ed. Maceió: UFAL/EDUFAL/FUNDEPES, 2000. 437p.

Flowers, T. J. Improving crop salt tolerance. Journal of Experimental Botany, v.55, p.307-319, 2004.

IBGE - Instituto Brasileiro de Geografia e Estatística. 2005. http:/ /www.ibge.gov.br/home/estatistica/indicadores/ agropecuaria/lspa/lspa_200910_7.shtm. 03 Jan. 2010.

Katerji, N.; van Hoorn, J. W.; Hamdy, A.; Mastrorilli, M. Salt tolerance classification of crops according to soil salinity and to water stress day index. Agricultural Water, v.43, p.99109. 2000 .

Liu, X.; Baird, W. V. Differential expression of genes regulated in response to drought or salinity stress in sunflower. Crop Science, v.43, p.678-687, 2003.
Mittova, V.; Tal, M.; Volokita, M.; Guy, M. Salt stress induces up-regulation of an efficient chloroplast antioxidant system in the salt-tolerant wild tomato species but not in the cultivated species. Physiologia Plantarum, v.115, p.393-400, 2002.

Monotti M. Growing non-food sunflower in dryland conditions. Italian Journal of Agronomy, v.8, p.3-8, 2004.

Neves, A. L. R.; Lacerda, C. F. de; Guimarães, F. V. A.; Hernandez, F. F. F.; Silva, F. B.; Prisco, J. T.; Gheyi, H. R. Acumulação de biomassa e extração de nutrientes por plantas de feijão-de-corda irrigadas com água salina em diferentes estádios de desenvolvimento. Ciência. Rural, v.39, p.758-765, 2009.

Nobre, R. G.; Gheyi, H. R.; Correia, K. G.; Soares, F. A. L.; Andrade, L. O. de. Crescimento e floração do girassol sob estresse salino e adubação nitrogenada. Revista Ciência Agronômica, v.41, p.358-367, 2010.

Novais, R. F.; Neves, J. C. L.; Barros, N. F. Ensaio em ambiente controlado. In: Métodos de pesquisa em fertilidade do solo. Brasília: Embrapa SEA p.392,1991.

Rhoades, J.; Kandiah, A.; Mashali, A. M. Uso de águas salinas para produção agrícola. Campina Grande: UFPB. 2000. 117p. Estudos FAO Irrigação e Drenagem 48.

Richards, L. A. Diagnosis and improvement of saline and alkali soils. Washington: U.S. Salinity Laboratoy. 1954.160p. Agriculture Handbook, 60.

Rubio, J. S.; García-Sánchez, F.; Rubio, F.; Martínez, V. Yield, blossom-end rot incidence, and fruit quality in pepper plants under moderate salinity are affected by $\mathrm{K}^{+}$and $\mathrm{Ca}^{2+}$ fertilization. Scientia Horticulturae, v.119, p.79-87, 2009.

Ruggiero, C.; Durii, J. F.; Goes, A. de. In: Ruggiero, C. (ed). Maracujá - do plantio a colheita. Jaboticabal: FCAVISBF. 1998. 388p.

Santana, M. J. de; Carvalho, J. de A.; Souza, K. J. de; Sousa, A. M. G. de; Vasconcelos, C. L.; Andrade, L. A. de B. Efeitos da salinidade da água de irrigação na brotação e desenvolvimento inicial da cana-de-açúcar (Saccharum spp) e em solos com diferentes níveis texturais. Ciência e Agrotecnologia. v.31, p.1470-1476, 2007.

Savvas, D.; Stamatib, E.; Tsirogiannisb, I. L.; Mantzosb, N.; Barouchasb, P.E; Katsoulasc, N.; Kittasc; C. Interactions between salinity and irrigation frequency in greenhouse pepper grown in closed-cycle hydroponic systems. Agricultural Water Management, v.91, p.102-111, 2007.

Silva, T. G. F. da; Zolnier, S.; Grossi, J. A. S.; Barbosa, J. G., Moura C. R. W.; Muniz, M. A. Crescimento do girassol ornamental cultivado em ambiente protegido sob diferentes níveis de condutividade elétrica de fertirrigação. Revista Ceres, v.56, p.602-610, 2009.

Tester, M.; Davenport, R. Na+ tolerance and $\mathrm{Na}^{+}$transport in higher plants. Annals of Botany, v.91, p.503-527, 2003. 